\title{
Xanthine Oxidase Inhibition by Aqueous Extract of Limonium brasiliense (Plumbaginaceae) ${ }^{\dagger}$
}

\author{
Silvana Andrea Rodriguez 1,2,*, Ana Paula Murray ${ }^{1}$ and José Manuel Leiro ${ }^{2}$ \\ 1 Departamento de Química, INQUISUR, UNS, B8000CPB Bahía Blanca, Argentina; apmurray@uns.edu.ar \\ 2 Laboratorio de Parasitología, IIAA, USC, E-15782 Santiago de Compostela, Spain; josemanuel.leiro@usc.es \\ * Correspondence: sarodrig@uns.edu.ar \\ + Presented at the 24th International Electronic Conference on Synthetic Organic Chemistry, \\ 15 November-15 December 2020; Available online: https://ecsoc-24.sciforum.net/.
}

Citation: Rodriguez, S.A.; Murray, A.P.; Leiro, J.M. Xanthine Oxidase Inhibition by Aqueous Extract of Limonium brasiliense

(Plumbaginaceae). Chem. Proc. 2021, 3, 123. https://doi.org/10.3390/ecsoc24-08410

Academic Editors: Julio A. Seijas and M. Pilar Vázquez-Tato

Published: 14 December 2020

Publisher's Note: MDPI stays neutral with regard to jurisdictional claims in published maps and institutional affiliations.

Copyright: $@ 2020$ by the authors. Licensee MDPI, Basel, Switzerland. This article is an open access article distributed under the terms and conditions of the Creative Commons Attribution (CC BY) license (http://creativecommons.org/licenses/by/4.0/).

\begin{abstract}
Limonium brasiliense (Boiss.) Kuntze (Plumbaginaceae) is a medicinal plant that is popularly used in the folk medicine. In this study, we examined xanthine oxidase (XO) inhibitory activity of the aqueous fraction of Limonium brasiliense extract and its polar bioactive constituents using the enzymatic hypoxanthine (HX)-XO system in vitro. Seven active compounds isolated from the aqueous extract proved to be strong XO inhibitors. Prodelphinidin B1-3,3'-digallate (1) showed the most potent inhibitory activity with an IC50 value of $6.61 \mu \mathrm{M}$, comparable to allopurinol. This study provides basis for the potential use of the aqueous fraction of L. brasiliense against hyperuricemia, displaying potent $\mathrm{XO}$ inhibitory activity with an IC 50 value of $48.3 \mu \mathrm{g} / \mathrm{mL}$. This inhibitory effect is compatible with the presence of $(\mathbf{1})$ in this extract.
\end{abstract}

Keywords: xanthine oxidase; inhibition; Limonium brasiliense; prodelphinidin B1-3,3'-digallate

\section{Introduction}

Xanthine oxidase $(\mathrm{XO})$ is an enzyme that catalyzes the oxidation of hypoxanthine and xanthine to uric acid; the inhibition of xanthine oxidase decreases uric acid accumulation in the joints, controlling the disease called gout, and is relevant for the treatment of hyperuricemia. Currently, gout is treated with the drug allopurinol (hypoxanthine ana$\log$ ). Prolonged use of allopurinol leads to adverse effects for health, since it controls but does not eliminate the uric acid overproduction [1], making it necessary to find new alternatives for control and gout prevention. XO inhibitors are also being investigated for management of reperfusion injury.

Oxidative stress, defined as an imbalance between levels of various oxidant molecules as reactive oxygen species (ROS) and antioxidants, leads to many biochemical changes and, consequently, serious disorders in the human organism. Oxidative stress can result in damage of biomolecules, such as lipids, proteins, and DNA, leading to cytotoxic and genotoxic effects. Although ROS are involved in host defense, overproduction of these species may contribute to the pathogenesis of inflammatory diseases and other immunopathological phenomena related to oxidative stress, such as rheumatoid arthritis, myocardial reperfusion injury, respiratory disorders, hepatocellular oxidative DNA injury, and pathogenesis of CNS neurons [2-7].

The inhibitory activity of xanthine oxidase is a combination of uric acid formation inhibition and superoxide anion $\left(\mathrm{O}_{2} \bullet-\right)$ generation suppression. The inhibition of uric acid formation by $\mathrm{XO}$ is useful for the screening of natural compounds that prevent gout, while the suppression of $\mathrm{O}_{2} \bullet-$ generation is useful for treating oxidative stress. The plants contain abundant phenolic compounds, and some of these compounds, such as flavonoid, have shown to inhibit $\mathrm{XO}$ and reactive oxygen species [8]. In recent studies, it has been 
demonstrated that $\mathrm{XO}$ inhibitory activity and the suppression of $\mathrm{O}_{2} \bullet-$ generation are used to characterize natural products [9].

Limonium brasiliense (Boiss.) Kuntze (Plumbaginaceae) is a medicinal plant known by its common name, "guaycurú", that grows mostly in saline soils distributed in Argentina, Uruguay, and South of Brazil. Infusion from the roots is popularly used in the treatment of hemorrhage, menstrual disorders, and rheumatism, and it is believed to have cardioprotective properties [10].

In previous studies, we evaluated the methanolic extract from the roots of L. brasiliense that showed antioxidant activity evidenced by the reduction of the stable free radical 2,2-diphenyl-1-picrylhydrazyl (DPPH) [11]. For this reason, we examined XO inhibitory activities of the aqueous fraction of L. brasiliense extract and its polar bioactive constituents using the enzymatic $\mathrm{HX}-\mathrm{XO}$ system in vitro. Our results suggest that the antioxidant activity of the aqueous fraction of $L$. brasiliense extract may be partially explained by an $\mathrm{O}_{2} \bullet-$ scavenging effect and by inhibition of $\mathrm{XO}$ activity.

For the first time, this study provides a new potential alternative for the use of $L$. brasiliense against hyperuricemia and for control and gout prevention.

\section{Material and Methods}

\subsection{General}

${ }^{1} \mathrm{H}$ and ${ }^{13} \mathrm{C}$ NMR spectra were recorded in DMSO- $d_{6}$ using tetramethylsilane (TMS) as internal standard on a Bruker ARX 300 multinuclear spectrometer at $300 \mathrm{MHz}$ and $75 \mathrm{MHz}$, respectively. UV spectra were recorded on a GBC spectral UV-VIS spectrophotometer.

Silica gel 60 (70-230 mesh, Fluka) was used for column chromatography, Dry Column Vacuum Chromatography (DCVC) with C18 silica, and semipreparative HPLC with a $\mathrm{C}_{18}$ Phenomenex Gemini column.

UV spectra were recorded on a GBC Spectral UV-VIS spectrophotometer and microplate UV/VIS reader (Titertek Multiscan, Flow Laboratories, Helsinki, Finland). Fluorescence emission was then determined in a microplate fluorescence reader (Bio-Tek Instruments, Jenway, United Kingdom; excitation $488 \mathrm{~nm}$, detection $530 \mathrm{~nm}$ ) over a $55 \mathrm{~min}$ period and microplate ELISA reader (Fluo-star Optima, BMG LABTECH, Offenburg, Germany).

Nitroblue tetrazolium (NBT), hypoxanthine (HX), xanthine, superoxide dismutase (SOD; from bovine erythrocytes), phosphate buffer $\left(\mathrm{KH}_{2} \mathrm{PO}_{4}-\mathrm{KOH}\right)$, Ethylenediaminetetraacetic acid disodium salt dihydrate (EDTA-Na2), allopurinol, and XO enzyme (from buttermilk) were all purchased from Sigma. Appropriate dilutions of the above drugs were prepared every day immediately before use in phosphate-buffered saline - PBS (XO assays) and/or in deionized water (for the other experiments) from the following concentrated stock solutions kept at $-20^{\circ} \mathrm{C}: \mathrm{SOD}(1 \mathrm{U} / \mathrm{mL})$ in deionized water, $\mathrm{HX}$ and xanthine $(10 \mathrm{mM})$ in a $0.1 \% w / v$ aqueous $\mathrm{KOH}$ solution, all other compounds $(100 \mathrm{mM})$ in deionized water. XO was dissolved daily before the experiments in PBS.

\subsection{Plant Material}

Roots of $L$. brasiliense were collected at Puerto Cuatreros ( $\left.38^{\circ} 45^{\prime} \mathrm{S}, 62^{\circ} 22^{\prime} \mathrm{O}\right)$, General Cerri, Buenos Aires province, Argentina, in February 2010. A voucher specimen was identified by Dr. María Gabriela Murray and was deposited in the Herbarium of Universidad Nacional del Sur (BBB) in Bahía Blanca, Argentina, under the number Murray, M.G. 421.

\subsection{Obtention of Aqueous Extract and Its Active Compounds}

Dried roots $(124.3 \mathrm{~g})$ were macerated overnight with ethanol $(\mathrm{EtOH})(1 \mathrm{~L})$. The ethanolic extract (EE) was evaporated in vacuo to yield $78.2 \mathrm{~g}$ of a brown residue that was dissolved in water $(200 \mathrm{~mL})$ and partitioned with hexane $(\mathrm{HF}, 3 \times 150 \mathrm{~mL})$. The aqueous 
fraction (AF) was evaporated, and the residue was lyophilized for 3 days (45.04 g). A portion of $\mathrm{AF}(0.7 \mathrm{~g})$ was submitted to DCVC chromatography with $\mathrm{C} 18$ silica and $\mathrm{H}_{2} \mathrm{O}: \mathrm{MeOH}$ as eluent (100:0, 90:10, 80:20, 70:30, 50:50, 30:70, 0:100). This procedure was repeated 5 times. Chromatographic separation was monitored by TLC, and the fractions were pooled according to their chromatographic profile in seven fractions, F1-F7. Fractions F2, F3, and F4 were selected for further chromatographic separation due to their activity in the DPPH assay. These fractions were submitted to semipreparative HPLC with a $\mathrm{C}_{18}$ Phenomenex Gemini column (5 $\mu \mathrm{m} \mathrm{C}_{18} 110 \AA$, 250 x $10 \mathrm{~mm}$ ) and $\mathrm{MeOH}: \mathrm{H}_{2} \mathrm{O}$ (50:50) as mobile phase $(1 \mathrm{~mL} / \mathrm{min})$. Absorbance was registered at $\lambda=254 \mathrm{~nm}$. Compound 7 $(8.2 \mathrm{mg})$ was isolated from the F2/A fraction and compound $1(31.9 \mathrm{mg})$ from the F2/C fraction, with retention times of 3.1 and $11.2 \mathrm{~min}$, respectively. Compound $6(20.3 \mathrm{mg})$ was isolated from the F3/A fraction and compound $2(29.4 \mathrm{mg})$ from the F/B fraction, with retention times of 8.7 and $10.8 \mathrm{~min}$, respectively.

Compound $3(61.4 \mathrm{mg})$ was obtained from F3/C and F4/C fractions, with a retention time of $25.2 \mathrm{~min}$. Compounds $4(30.5 \mathrm{mg})$ and $5(6.1 \mathrm{mg})$ were obtained from F4/A and F4/B fractions, with retention times of 16.5 and $18.3 \mathrm{~min}$, respectively. All compounds were characterized by ${ }^{1} \mathrm{H}$ and ${ }^{13} \mathrm{C}$ NMR.

\subsection{Xanthine Oxidase Activity}

Generation of $\mathrm{O}_{2} \bullet$ - by use of the enzymatic hypoxanthine oxidase the HX-XO system.

The superoxide ion $\left(\mathrm{O}_{2} \bullet-\right)$ was generated enzymatically in an HX-XO system and quantified by the spectrophotometric measurement of the product of the reduction of NBT, essentially following the procedure described by Orallo et al. [12] using $250 \mu \mathrm{L}$ of test solution of $1 \mathrm{mM}$ EDTA-Na2, $100 \mu \mathrm{M}$ HX, $100 \mu \mathrm{M}$ NBT in phosphate buffer $(50 \mathrm{mM}$ $\left.\mathrm{KH}_{2} \mathrm{PO}_{4}-\mathrm{KOH}, \mathrm{pH} 7.4\right)$ and $\mathrm{EE}$ or $\mathrm{AF}$ extracts $(0.1-250 \mu \mathrm{g} / \mathrm{mL})$ and compounds $1-7$ $(0.1-500 \mu \mathrm{M})$. Control experiments were carried out simultaneously using the same test solution but without extract. The reaction was started with the test solution already in a Cobas Fara 22-3123 AutoAnalyzer (Roche) by adding XO in phosphate buffer $(0.066 \mathrm{U} / \mathrm{mL})$ and continued at room temperature $\left(22-24^{\circ} \mathrm{C}\right)$ for $10 \mathrm{~min}$. The rate of NBT reduction was estimated from the difference in absorbance at $560 \mathrm{~nm}$ between the test solution and a blank solution in which the $\mathrm{XO}$ was replaced by buffer solution. In some experiments, the sensitivity of the method was evaluated by assessing the influence of SOD $(1 \mathrm{U} / \mathrm{mL})$, a known scavenger of $\mathrm{O}_{2} \bullet-$.

Determination of $\mathrm{XO}$ activity by use of the $\mathrm{XO}$ system.

The potential effect of L. brasiliense extracts and compounds 1-7 on XO activity was investigated by measuring uric acid formation, as previously described (Orallo et al. 2002). Briefly, $1 \mathrm{~mL}$ of test solutions of phosphate buffer $\left(50 \mathrm{mM} \mathrm{KH_{2 }} \mathrm{PO}_{4}-\mathrm{KOH}\right.$, $\mathrm{pH}$ 7.4) containing the EE or the AF extract at different concentrations $(0.1-250 \mu \mathrm{g} / \mathrm{mL})$ and compounds $1-7$ at different concentrations $(0.1-500 \mu \mathrm{M})$, EDTA-Na2 $(1 \mathrm{mM})$, and $0.066 \mathrm{U}$ of XO were incubated for $15 \mathrm{~min}$ at room temperature. The reaction was started by adding xanthine in phosphate buffer $(100 \mu \mathrm{M})$, and the rate of uric acid production was estimated from the difference in absorbance at $295 \mathrm{~nm}$ (measured at room temperature for $10 \mathrm{~min}$ in a UVvisible absorption spectrophotometer, Shimadzu UV-240, Duisburg, Germany) between the test solution and a blank solution in which $\mathrm{XO}$ was replaced by buffer solution. In some assays, the validity of the method was confirmed by assessing the influence of allopurinol (a well-known XO inhibitor) on uric acid formation.

\subsection{Antioxidant Activity}

Determination of DPPH assay.

The antioxidant activity was evaluated through the ability as free radical scavenger of extracts, fractions, and/or pure compounds, as described Bors et al. [13]. The preliminary test was performed with a rapid TLC screening method using the 2,2-diphenyl-1- 
picrylhydrazyl radical. Analytical TLC on reverse plates was developed with appropriate conditions after application of $5 \mu \mathrm{L}$ of each test compound solution $(1 \mathrm{mg} / \mathrm{mL})$, dried, and sprayed with DPPH solution $(0.2 \%, \mathrm{MeOH})$. A total of 5 min later, active compounds appeared as yellow spots against a purple background. The purple stable free radical 2,2diphenyl-1-picrylhydrazyl was reduced to the yellow colored diphenylpicryl hydrazine. Quercetin was used as positive control.

\subsection{Statistical Analysis}

Statistical analysis was performed using Tukey-Kramer correction of a one-way ANOVA test using Graph-Pad Prism 5.0 software. The results are expressed as means standard errors of the means (SEM). The concentration of drugs that caused a 50\% inhibition of the response $\left(\mathrm{IC}_{50}\right)$ was estimated by nonlinear regression analysis (GraphPad Prism software; GraphPad, San Diego, CA, USA) from the concentration-response curves obtained in each case.

\section{Results and Discussion}

\subsection{Extraction and Isolation}

Dried roots of L. brasiliense were milled and macerated with ethanol to obtain ethanolic extract (EE) that was dissolved in water (AF) and partitioned with hexane (HF). AF was submitted to chromatographic separations to render seven pure compounds that were identified as prodelphinidin B1-3,3'-digallate (1), myricetin (2), apigenin (3), taxifolin (4), 3-O-acetyltaxifolin (5), myricetin-3-O- $\alpha$-rhamnopyranoside (6), and gallic acid (7). Identification was achieved on the basis of their ${ }^{1} \mathrm{H}$ and ${ }^{13} \mathrm{C}$ NMR spectra and by comparison with literature data [14-16]

\subsection{Xhanthine Oxidase Activity}

$\mathrm{XO}$ catalyzes the formation of uric acid and ROS during the catabolism of purines, and excess of uric acid can lead to increased oxidative stress, mutagenesis, and possibly to cancer development [17]. In recent studies, it has been demonstrated that XO inhibitory activity and the suppression of $\mathrm{O}_{2} \bullet-$ generation are used to characterize natural products. It has been reported that $\mathrm{XO}$ converts $\mathrm{HX}$ or xanthine to uric acid, $\mathrm{H}_{2} \mathrm{O}_{2}$, and $\mathrm{O}_{2} \bullet-$ [18]. $\mathrm{O}_{2} \bullet$ - generated by this system reacts with NBT to produce formazan (NBT is reduced in the reaction). The formation of this colored compound (formazan) and the amount of $\mathrm{O}_{2} \bullet-$ generated enzymatically may be measured spectrophotometrically [19]. When a drug lowers the amount of $\mathrm{O}_{2} \bullet$ - (i.e., the reduction of NBT) and at the same time does not affect the formation of uric acid, it is considered to be a selective scavenger of $\mathrm{O}_{2} \bullet-$. On the other hand, if a drug inhibits $\mathrm{XO}$ activity, both uric acid and $\mathrm{O}_{2} \bullet-$ concentrations are diminished.

$\mathrm{XO}$ is a key enzyme which can catalyze hypoxanthine and xanthine to uric acid causing hyperuricemia in humans. In this study, we examined XO inhibitory activities of the aqueous fraction of L. brasiliense extract and its polar bioactive constituents using the enzymatic HX-XO system in vitro, which can be measured spectrophotometrically.

Superoxide-scavenging activity of the aqueous fraction and isolated compounds of L. Brasiliense.

To investigate the possible superoxide scavenging activity, we performed assays in which $\mathrm{O}_{2} \bullet-$ was generated by an enzymatic system (HX-XO). EE and AF at concentrations between 0.1 and $250 \mu \mathrm{g} / \mathrm{mL}$ significantly reduced medium concentrations of $\mathrm{O}_{2} \bullet$-, with the inhibitory effect with IC 50 values of $42.03 \pm 1.04 \mu \mathrm{g} / \mathrm{mL}$ and $10.86 \pm 1.25 \mu \mathrm{g} / \mathrm{mL}$, respectively (Figure 1).

In this assay, myricetin (2) and myricetin-3-O- $\alpha$-rhamnopyranoside (6) showed a significant superoxide scavenging activity with IC 50 values of $6.04 \pm 1.51 \mu \mathrm{M}$ and $18.96 \pm 1.36 \mu \mathrm{M}$, respectively. A moderate effect was observed for taxifolin (4) with an $\mathrm{IC}_{50}=35.93 \pm 1.65 \mu \mathrm{M}$. Neither apigenin (3) (IC50 67.21 $\pm 1.35 \mu \mathrm{M})$ nor gallic acid (7) $\left(\mathrm{IC}_{50} 126.13 \pm 2.06 \mu \mathrm{M}\right)$ had significant effects. 
Prodelphinidin B1-3,3'-digallate (1) showed the most potent superoxide scavenging activity with an IC 50 value of $1.58 \pm 0.34 \mu \mathrm{M}$ (Figure 2).

The results obtained for each sample are summarized in Figures 1 and 2 and Table 1.

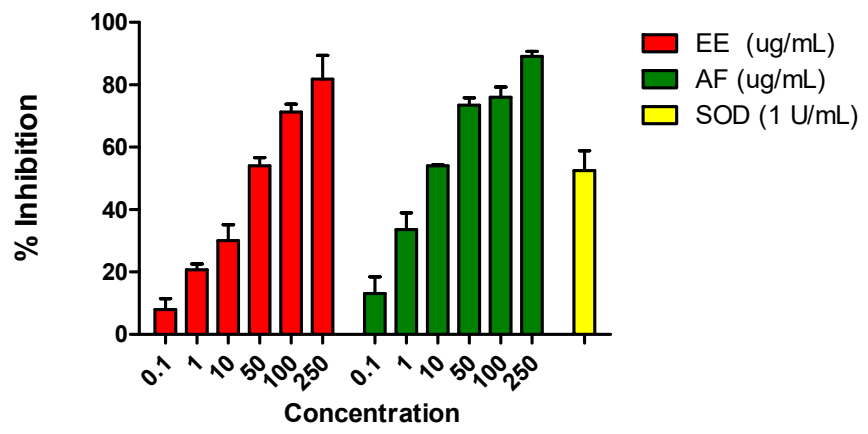

Figure 1. Effects of the ethanolic extract (EE) and the aqueous fraction (AF) $(0.1-250 \mu \mathrm{g} / \mathrm{mL})$ of $L$. brasiliense on reduction of nitroblue tetrazolium (NBT) by $\mathrm{O}_{2} \bullet-$ generated by xanthine oxidase (XO) in the presence of $100 \mu \mathrm{M}$ hypoxanthine (HX). The rightmost bar represents assays in which the enzyme superoxide dismutase (SOD; $1 \mathrm{U} / \mathrm{mL}$ ) was added to cultures instead of $\mathrm{EE}$ and $\mathrm{AF}$; this enzyme abolishes superoxide generation in the HX-XO system. Values shown are mean percentages of the control response $(\mathrm{n}=3) \pm$ SEM. Asterisks indicate statistical significance $(p<0.001)$.

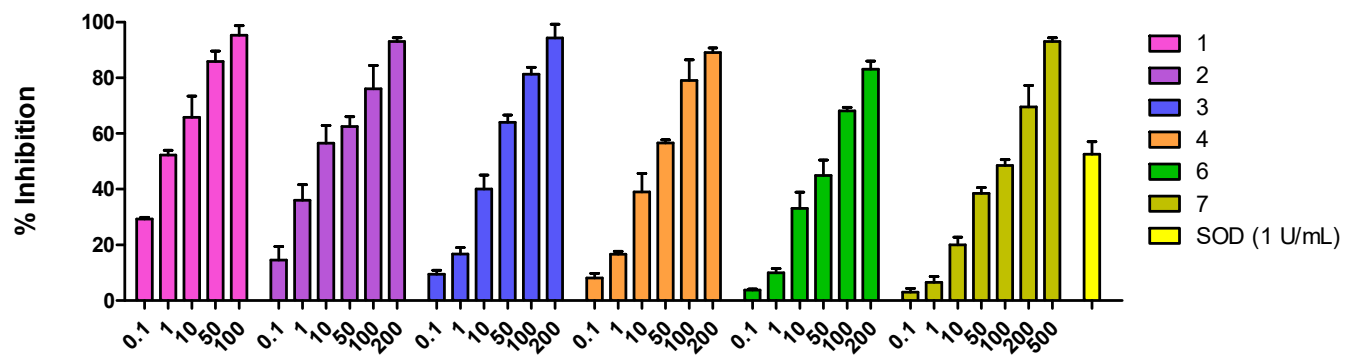

Figure 2. Effects of the compounds 1-7 $(0.1-500 \mu \mathrm{M})$ on reduction of NBT by $\mathrm{O}_{2} \bullet-$ generated by XO in the presence of $100 \mu \mathrm{M} \mathrm{HX}$. The rightmost bar represents assays in which the enzyme superoxide dismutase (SOD; $1 \mathrm{U} / \mathrm{mL}$ ) was added to cultures instead of EE and AF; this enzyme abolishes superoxide generation in the $\mathrm{HX}-\mathrm{XO}$ system. Values shown are mean percentages of the control response $(\mathrm{n}=3) \pm$ SEM. Asterisks indicate statistical significance $(p<0.001)$.

Table 1. IC 50 values SOD and XO of extracts and isolated compounds obtained from L. brasiliense.

\begin{tabular}{|c|c|c|}
\hline Antioxidants & $\mathrm{IC}_{50} \mathrm{SOD}^{\mathrm{a}}$ & $\mathrm{IC}_{50} \mathrm{XO} \mathrm{a}^{\mathrm{a}}$ \\
\hline allopurinol $^{\mathrm{b}}$ & N.T & $3.61 \pm 0.05^{c}$ \\
\hline EE & $42.03 \pm 1.04 \mathrm{~d}$ & $96.14 \pm 2.09 \mathrm{~d}$ \\
\hline $\mathrm{AF}$ & $10.86 \pm 1.25 \mathrm{~d}$ & $48.3 \pm 1.63 \mathrm{~d}$ \\
\hline prodelphinidin B1-3,3'-digallate (1) & $1.58 \pm 0.34^{\mathrm{c}}$ & $6.61 \pm 0.13^{c}$ \\
\hline myricetin (2) & $6.04 \pm 1.51^{c}$ & $16.89 \pm 1.03 c$ \\
\hline apigenin (3) & $67.21 \pm 1.35 \mathrm{c}$ & $19.01 \pm 1.10^{c}$ \\
\hline taxifolin (4) & $35.93 \pm 1.65^{c}$ & $31.58 \pm 0.36 c$ \\
\hline myricetin-3-O- $\alpha$-rhamnopyranoside (6) & $18.96 \pm 1.36^{c}$ & $167.02 \pm 1.02 c$ \\
\hline gallic acid (7) & $126.13 \pm 2.06^{c}$ & $213.24 \pm 1.61 \mathrm{c}$ \\
\hline
\end{tabular}

a Values are the mean \pm S.E.M. of three replicas. ${ }^{b}$ Positive control ${ }^{c} \mu \mathrm{M} .{ }^{\mathrm{d}} \mu \mathrm{g} / \mathrm{mL}$. NT not tested.

Effects of the aqueous fraction and compounds 1-7 on XO activity.

The effects of aqueous fraction of $L$. brasiliense extract and its polar bioactive constituents (1-7) on $\mathrm{XO}$ activity were investigated by measuring their ability to affect the formation of uric acid from xanthine. 
Only AF showed inhibition of uric acid formation and thus $\mathrm{XO}$ activity with an IC50 value of $48.30 \pm 1.63 \mu \mathrm{g} / \mathrm{mL}$, while EE showed a moderate inhibition of uric acid formation $\left(\mathrm{IC}_{50}=96.14 \pm 2.09 \mu \mathrm{g} / \mathrm{mL}\right.$ ) (Figure 3).

As is shown in Figure 4, neither myricetin-3-O- $\alpha$-rhamnopyranoside (6) (IC $\mathrm{C}_{50} 167.02$ $\pm 1.02 \mu \mathrm{M})$ nor gallic acid $(7)\left(\mathrm{IC}_{50} 213.24 \pm 1.61 \mu \mathrm{M}\right)$ had significant effects, while taxifolin (4) elicited a moderate inhibition of uric acid formation $\left(\mathrm{IC}_{50}=31.58 \pm 0.36 \mu \mathrm{g} / \mathrm{mL}\right.$ ). On the other hand, myricetin (2) and apigenin (3) showed a significative inhibition of XO activity with IC 50 values of $16.89 \pm 1.03 \mu \mathrm{M}$ and $19.01 \pm 1.10 \mu \mathrm{M}$, respectively.

Prodelphinidin B1-3,3'-digallate (1) showed the most potent inhibitory activity with an IC 50 value of $6.61 \pm 0.13 \mu \mathrm{M}$, comparable to allopurinol, the drug of choice for inhibition of $\mathrm{XO}$ in gout patients.

The results obtained for each sample are summarized in Figures 3 and 4 and Table 1.

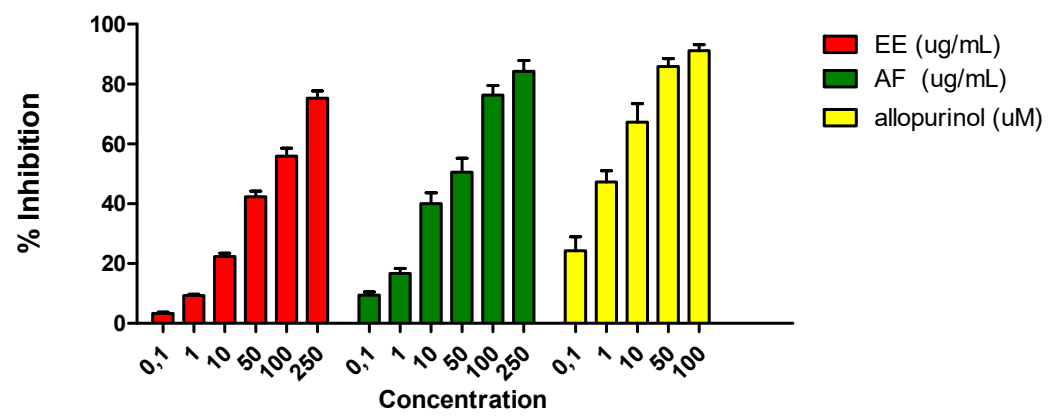

Figure 3. Effects of EE and AF $(0.1-250 \mu \mathrm{g} / \mathrm{mL})$ of L. brasiliense on uric acid production by XO in the presence of $100 \mu \mathrm{M}$ xanthine. The rightmost bar represents assays in which the XO inhibitor allopurinol was added. Values shown are means percentages of the control response $(n=3) \pm S E M$. Asterisks indicate statistical significance $(p<0.001)$.

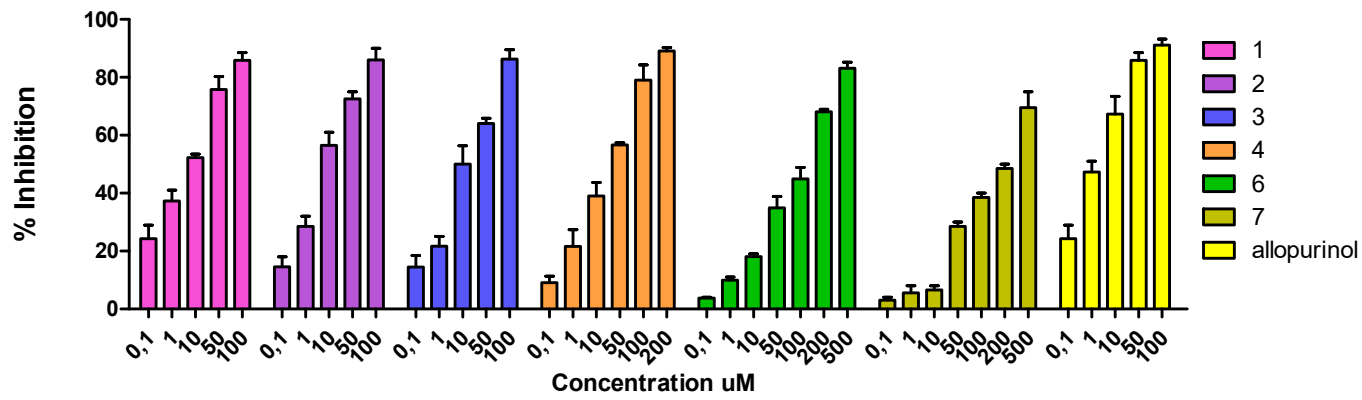

Figure 4. Effects of the compounds 1-7 (0.1-500 $\mu \mathrm{M})$ of L. brasiliense on uric acid production by $\mathrm{XO}$ in the presence of $100 \mu \mathrm{M}$ xanthine. The rightmost bar represents assays in which the $\mathrm{XO}$ inhibitor allopurinol was added. Values shown are means percentages of the control response $(n=3) \pm S E M$. Asterisks indicate statistical significance $(p<0.001)$.

\section{Conclusions}

In the present study, the effects of the aqueous fraction of $L$. brasiliense extract, and its polar bioactive constituents on $\mathrm{XO}$ activity were investigated by measuring their ability to affect the formation of uric acid from xanthine using the enzymatic $\mathrm{HX}-\mathrm{XO}$ system in vitro and oxidative stress inhibition using $\mathrm{O}_{2} \bullet-$ scavenging effect.

The aqueous fraction of L. brasiliense displayed potent $\mathrm{XO}$ inhibitory activity with an $\mathrm{IC}_{50}$ value of $48.3 \pm 1.63 \mu \mathrm{g} / \mathrm{mL}$. Our result suggests that the antioxidant activity of the aqueous fraction of L. brasiliense extract previously reported [11] may be partially explained by an $\mathrm{O}_{2} \bullet-$ scavenging effect ( $\mathrm{IC}_{50} 10.86 \pm 1.25 \mu \mathrm{g} / \mathrm{mL}$ ) and by inhibition of xanthine oxidase activity. 
This inhibitory effect is compatible with the presence of flavonoid compounds in this aqueous fraction. It has been previously demonstrated that myricetin (2) and apigenin (3) can inhibit XO activity [20].

Prodelphinidin B1-3,3'-digallate (1) was effective for scavenging superoxide radicals $\left(\mathrm{O}_{2} \bullet^{-}\right)\left(\mathrm{IC}_{50} 1.58 \pm 0.13 \mu \mathrm{M}\right)$, generated enzymatically by a hypoxanthine/xanthine oxidase system and for inhibiting XO activity. This compound showed the most potent XO inhibitory activity with an $\mathrm{IC}_{50}$ value of $6.61 \pm 0.13 \mu \mathrm{M}$, at the same level as allopurinol, the drug of choice for inhibition of $\mathrm{XO}$ in gout patients. These results clearly indicate that 1 displays selective $\mathrm{O}_{2} \bullet-$ scavenging and direct inhibitory $\mathrm{XO}$ properties.

In conclusion, the aqueous fraction of L. brasiliense extract significantly inhibits ROS production, both by inhibiting XO and by scavenging ROS already produced. It seems likely that these activities are attributable to prodelphinidin B1-3,3'-digallate (1) present in the extract.

For the first time, this study provides a new alternative for the use of aqueous fraction of L. brasiliense against hyperuricemia and for control and gout prevention. Thus, flavonoids could be used as a preventive and therapeutic agent for gout. In addition, they might be useful as a biochemical probe, taking advantage of their potent inhibitory activities.

Institutional Review Board Statement: Not applicable.

Informed Consent Statement: Not applicable.

\section{References}

1. Keenan, R.T.; O’Brien, W.R.; Lee, K.H.; Crittenden, D.B.; Fisher, M.C.; Goldfarb, D.S.; Krasnokutsky, S.; Oh, C.; Pillinger, M.H. Prevalence of Contraindications and Prescription of Pharmacologic Therapies for Gout. Am. J. Med. 2011, 124, 155-163.

2. Darley-Usmar, V.; Wiseman, H.; Halliwell, B. Nitric oxide and oxygen radicals: A question of balance. FEBS Lett. 1995, 309, 131135.

3. Klimiuk, P.A.; Sierakowski, S.; Latosiewicz, R.; Cylwik, B.; Skowronski, J.; Chwiecko, J. Serum cytokines in different histological variants of rheumatoid arthritis. J. Rheumatol. 2001, 28, 1211-1217.

4. Bell, D.; Jackson, M.; Nicoll, J.J. Inflammatory response, neutrophil activation, and free radical production after acute myocardial infarction: Effect of thrombolytic treatment. Br. Heart J. 1990, 63, 82-87.

5. Li, C.; Jackson, R.M. Reactive species mechanisms of cellular hypoxia-reoxygenation injury. Am. J. Physiol. Cell Physiol. 2002, 282, 227-241.

6. Watanabe, N.; Miura, S.; Zeki, S.; Ishii, H. Hepatocellular oxidative DNA injury induced by macrophage-derived nitric oxide. Free Radical. Biol. Med. 2001, 30, 1019-1028.

7. Satoh, T.; Numakawa, T.; Abiru, Y. Production of reactive oxygen species and release of L-glutamate during superoxide anioninduced cell death of cerebellar granule neurons. J. Neurochem. 1998, 70, 316-324.

8. Nagao, A.; Seki, M.; Kobayashi, H. Inhibition of Xanthine Oxidase by Flavonoids. Biosci. Biotechnol. Biochem. 1999, 63, 1787-1790.

9. Nessa, F.; Saeed, A.K. Evaluation of antioxidant and xanthine oxidase inhibitory activity of different solvent extracts of leaves of Citrullus colocynthis. Pharmacogn. Res. 2014, 3, 218-226.

10. Gupta, M.P. 270 Plantas Medicinales Iberoamericanas; CYTED-SECAB: Bogotá, Colombia, 1995, pp. 21-24.

11. Murray, A.P.; Rodriguez, S.; Frontera, M.A.; Tomas, M.A.; Mulet, M.C. Antioxidant metabolites from Limonium brasiliense (Boiss.) kuntze. Z. Nat. Sect C J. Biosci. 2004, 59, 477-480.

12. Orallo, F.; Alvarez, E.; Camina, M.; Leiro, J.M.; Gomez, E.; Fernandez, P. The possible implication of trans-resveratrol in the cardioprotective effects of long-term moderate wine consumption. Mol. Pharmacol. 2002, 61, 294-302.

13. Bors, W.; Saran, M.; Eltsner, E.F. Screening for plants antioxidants. In Modern Methods of Plant Analysis New Series; Plant Toxin Analysis; Linskens, H.F., Jackson, J.F., Eds.; Springer: Berlin/Heidelberg, Germany, 1992; Volume 13, pp. $277-295$.

14. Agrawal, P.K. Carbon-13 NMR of Flavonoids; Elsevier: Amsterdam, The Netherlands, 1989.

15. Markham, K.R.; Ternai, B.; Stanley, R.; Geiger, H.; Mabry, T.J. Carbon-13 NMR studies of flavonoids-III: Naturally occurring flavonoid glycosides and their acylated derivatives. Tetrahedron 1978, 34, 1389-1397.

16. Shen, C.C.; Chang, Y.S.; Hott, L.K. Nuclear magnetic resonance studies of 5,7-dihydroxyflavonoids. Phytochemistry 1993, 34, 843-845. 
17. Aucamp, J.; Gaspar, A.; Hara, Y.; Apostolides, Z. Inhibition of xanthine oxidase by catechins from tea (Camellia sinensis). Anticancer Res. 1997, 17, 4381-4385.

18. Wippich, N.I.C.O.; Peschke, D.O.R.O.T.H.E.E.; Peschke, E.L.M.A.R.; Holtz, J.Ü.R.G.E.N.; Bromme, H.J. Comparison between xanthine oxidases from buttermilk and microorganisms regarding their ability to generate reactive oxygen species. Int. J. Mol. Med. 2001, 7, 211-216.

19. Zhao, J.; Huang, L.; Sun, C.; Zhao, D.; Tang, H. Studies on the structure-activity relationship and interaction mechanism of flavonoids and xanthine oxidase through enzyme kinetics, spectroscopy methods and molecular simulations. Food Chem. 2020, 323, 126807, doi:10.1016/j.foodchem.2020.126807.

20. Mohos, V.; Fliszár-Nyúl, E.; Poór, M. Inhibition of Xanthine Oxidase-Catalyzed Xanthine and 6-Mercaptopurine Oxidation by Flavonoid Aglycones and Some of Their Conjugates. Int. J. Mol. Sci. 2020, 21, 3256-3266. 